\title{
Oversight Committee Effective Date Range
}

National Cancer Institute

\section{Source}

National Cancer Institute. Oversight Committee Effective Date Range. NCI Thesaurus.

Code C93884.

The date and time span for when the oversight committee is active. 